\title{
Interaction between cytochrome P450 2A6 and Catechol-O-Methyltransferase genes and their association with smoking risk in young men
}

Wei-Chih Ou ${ }^{1 \dagger}$, Yi-Chin Huang ${ }^{5 \dagger}$, Chih-Ling Huang ${ }^{2}$, Min-Hsuan Lin ${ }^{3}$, Yi-Chun Chen ${ }^{3}$, Yi-Ju Chen ${ }^{4}$, Chen-Nu Liu', Mei-Chih Chen ${ }^{1}$, Ching-Shan Huang ${ }^{3^{*} \ddagger}$ and Pei-Lain Chen ${ }^{1 *} \neq$ (1)

\begin{abstract}
Background: Although some effects of gene-gene interactions on nicotine-dopamine metabolism for smoking behavior have been reported, polymorphisms of cytochrome P450 (CYP) 2A6 and catechol-O-methyltransferase (COMT) have not been studied together to determine their effects on smokers. The aim of this study was to investigate the effects of the interaction between the CYP 2A6 and COMT genes on smoking behavior in young Taiwanese men.

Results: A self-report questionnaire regarding smoking status was administered to 500 young men. Polymorphisms of the CYP $2 A 6$ and COMT genes as well as urinary nicotine and urinary cotinine levels were determined. The odds ratio for starting smoking was significantly lower in subjects carrying a CYP2A6 low activity/variant COMT rs4680 genotype than in those possessing a CYP2A6 wild-type/variant COMT rs4680 genotype (0.44, 95\% confidence inter$\mathrm{val}=0.19-0.98, \mathrm{P}=0.043)$. Comparisons of Fagerstrom Test for Nicotine Dependence (FTND), Physiological Cigarette Dependence Scale (PCDS), and Cigarette Withdrawal symptoms (CWS-21) among the smokers with different CYP2A6/ COMT polymorphisms were not significantly different. The adjusted urinary nicotine concentrations were not significantly different between the two groups carrying different genotypes. The adjusted urinary cotinine level was significantly different between the COMT rs4680 wild-type group and COMT rs4680 variant group $[92.46 \mathrm{ng} / \mathrm{\mu L}$ vs. $118.24 \mathrm{ng} / \mu \mathrm{L}$ (median value), $\mathrm{P}=0.041$ ] and between the COMT rs4680 wild-type/COMT rs 165599 variant group and COMT rs4680 variant/COMT rs 165599 variant group ( $97.10 \mathrm{ng} / \mu \mathrm{L}$ vs. $122.18 \mathrm{ng} / \mu \mathrm{L}, \mathrm{P}=0.022)$.
\end{abstract}

Conclusions: These findings suggest that a single nucleotide polymorphism (rs4680) of the COMT gene and the interaction between the CYP $2 A 6$ and COMT genes affect smoking status in young Taiwanese men.

Keywords: Catechol-O-methyltransferase, Cotinine, Cytochrome P450 2A6, Nicotine, Smoking status

\section{Background}

Tobacco smoking is a multi-factorial behavior with both genetic and environmental determinants [1]. Genetic

\footnotetext{
*Correspondence: ching.shan.h@gmail.com; plchen@ctust.edu.tw ${ }^{\dagger}$ Wei-Chih Ou and Yi-Chin Huang contributed equally to this work

${ }^{\ddagger}$ Ching-Shan Huang and Pei-Lain Chen contributed equally to this work ${ }^{1}$ Department of Medical Laboratory Science and Biotechnology, Central Taiwan University of Science and Technology, No. 666 Buzih Road, Beitun District, Taichung City 40601, Taiwan

${ }^{3}$ Administration Center for Research and Education, Changhua Christian Hospital, Changhua, Taiwan

Full list of author information is available at the end of the article
}

factors have a greater influence on smoking cessation than do environmental factors [2]. Genetic factors are responsible for $30-50 \%$ of the variance in the risk of withdrawal symptoms, $40-75 \%$ of the variation in smoking initiation, $50 \%$ of the variance in cessation success, and $70-80 \%$ of the variation in smoking maintenance [1]. Genetic risk information enhances the motivation for smoking cessation [3]. Therefore, assessment of genetic background could be a promising tool to understand smoking risk and to guide the selection of the most effective cessation treatment for an individual smoker. 
Nicotine is the major psychoactive ingredient in tobacco, and it modulates dopamine activity in the midbrain, which contributes to the development and maintenance of rewarding behaviors such as smoking [4]. Smokers modulate their smoking to maintain brain nicotine levels within a certain concentration range, and factors that alter nicotine clearance affect smoking behavior [4]. Individuals who eliminate nicotine rapidly are less likely to achieve low craving scores even after smoking freely [4]. Consequently, genetic polymorphisms in both nicotine metabolism and dopamine catabolism genes influence smoking status, interact with each other to result in risk modulation, and affect smoking cessation therapies.

The cytochrome P450 (CYP) 2A6 gene, located on chromosome 19q12-q13.2, consists of nine exons. It is involved in producing a 494-amino-acid protein that oxidizes coumarin, nicotine, and tobacco-specific nitrosamines [5]. CYP2A6 is the primary human enzyme involved in nicotine metabolism [4]. CYP2A6 catalyzes the $\mathrm{C}$-oxidation of nicotine to the inactive metabolite cotinine and the subsequent conversion of cotinine into trans-3'-hydroxycotinine [4]. CYP2A6 is the most studied enzyme involved in both adult and adolescent smokers [6]. The results of studies among Taiwanese individuals indicate that the variant status of CYP2A6 is different from that among other ethnic groups [7]. Therefore, we hypothesized that, for Taiwanese individuals, polymorphisms in the CYP2A6 gene that affect smoking status could be different from those in other ethnic groups.

The catechol-O-methyltransferase (COMT) gene is located on chromosome 22q11.21, has eight exons, and produces a 271-amino-acid protein that metabolizes catecholamines [8]. Low enzyme activity of the Met allele at codon 108/158 (in the rs4680 polymorphism) of the COMT gene, which encodes a key enzyme involved in the metabolic inactivation of dopamine, has been associated with nicotine dependence [9]. Another polymorphism of COMT, rs165599, has been related to the response to bupropion therapy for smoking cessation [10]. However, those associations have been inconsistent among ethnic groups $[10,11]$. Thus, it seems necessary to perform a genetic study of smoking status for each ethnicity.

Smoking addiction is currently a significant social problem in Taiwan [12]. Nonetheless, very few genetic investigations of nicotine-dopamine metabolism and smoking status among Taiwanese individuals have been performed. Recently, for Taiwanese smokers in a group of methadone maintenance patients, polymorphisms of the $\mu$-opioid receptor gene were associated with the plasma concentration of cotinine [13]. Very recently, our team reported that the interaction of the dopamine D2 receptor (DRD2) TaqIB and monoamine oxidase A (MAOA) affected smoking intensity in young men [14]. Those findings encouraged us to perform more genetic studies of Taiwanese smokers. In relation to nicotine-dopamine metabolism, smoking status has been reported to correlate better with some gene-gene interactions than with a single gene only. These interactions include COMT and $M A O A$ [15, 16], MAOA and CYP2A6 [17], CYP2A6 and the nicotine acetylcholine receptor gene $[18,19]$, and CYP $2 A 6$ and DRD2 TaqIA [20]. However, the effects of CYP2A6 and COMT together have not been explored, and we hypothesized that a single polymorphism as well as an interaction of the two genes could be involved in smoking status.

In women not using oral contraceptives, nicotine and cotinine clearance is 13 and $24 \%$ higher, respectively, than in men [6]. Sex differences exist for cravings, affect, and preference for immediate smoking after cue exposure [21]. Because Taiwanese men smoke significantly more cigarettes than Taiwanese women [12, 22], only men were invited to participate in our study. In this study, the polymorphisms CYP2A6*1A (wild-type), CYP 2A6*1B (polymorphism of faster nicotine clearance) [23], CYP2A6*4C (the most studied polymorphism of decreased nicotine metabolism) [24], COMT Val/Met (rs4680) [9], and COMT rs165599 [10] were determined. Our objectives were to investigate the effects of the interaction between the CYP $2 A 6$ and COMT genes and their association with smoking risk in young Taiwanese men.

\section{Methods}

\section{Participants and procedures}

This cross-sectional study was advertised to all students at both Chang Jung Christian University and Central Taiwan University of Science and Technology. The volunteers contacted the authors of the study, and convenience samples were then screened for eligibility at the health centers of the two universities. All study subjects provided written, informed consent at the beginning of study, and the study was approved by the review board of Chang Jung Christian University (CJCU-99004) and Central Taiwan University of Science and Technology (CTUST-99016). The study was conducted in accordance with Good Clinical Practice procedures and the Declaration of Helsinki.

We administered a self-report questionnaire to all of the study subjects [25-27]. The questionnaire included demographic data, smoking background and status. In addition, the questionnaire included the fagerstrom test for nicotine dependence (six-item FTND) [25], the 15-item short form of the Physiological Cigarette Dependence Scale (PCDS) derived from the 30-item PCDS [27], and the Withdrawal Symptoms Scale (Cigarette Withdrawal Scale, CWS-21) [26, 27]. These 
questionnaires used biomarkers (nicotine and cotinine concentrations) as validation, with no over- or underexaggeration. Never smokers were defined as persons who had never smoked in their lifetime. Current smoking was defined as ever smoking cigarettes on 1 or more days of the past 30 days. Ever smokers were defined as persons who smoked at one time, had quit, and were not currently smoking. The current smokers were divided into two groups according to their intensity of cigarette smoking: light smokers and heavy smokers, depending on number of cigarettes per day lower than or equal to (or higher than) the average value of all the smokers, respectively. The exclusion criteria were (1) a history of diagnosed mental health disease or cancer, (2) alcoholism or drug abuse, (3) severe communication problems, or (4) terminal illness. When the survey was completed, blood and urine samples were obtained at a university center by trained research assistants (licensed nurses or medical technologists).

\section{Determination of CYP2A6 and COMT polymorphisms}

In this study, to determine the genotypes of the variants of interest, total genomic DNA was isolated from blood cells using a blood DNA isolation kit (Favorgen, Ping-Tung, Taiwan). Five milliliters of whole blood with EDTA as an anticoagulant were required. Approximately 40 alleles of the CYP2A6 gene have been identified [28]. However, only the wild-type (CYP2A6*1A) and two highly prevalent $(>10 \%)$ variants of $C Y P 2 A 6^{* 1 B}$ (approximately 45\%) [29] and CYP2A6*4C (approximately 15\%) [30], which have been observed in Chinese individuals, were determined in this project.

The polymorphisms of CYP2A6 were identified using polymerase chain reaction-restriction fragment length polymorphism (PCR-RFLP) [31]. We designed the forward primer 5'-CACCGAAGTGTTCCCTATG CTG-3' ${ }^{\prime}$ and reverse primer $5^{\prime}$-TGTAAAATGGGCATG AACGCCC-3' according to the GenBank accession system. PCR was performed with a thermal cycler (Bio-Rad, Carlsbad, CA, USA). The PCR conditions were as follows: first cycle, denaturation at $94{ }^{\circ} \mathrm{C}$ for $3 \mathrm{~min}$; cycles 2-31, denaturation at $94{ }^{\circ} \mathrm{C}$ for $1 \mathrm{~min}$, annealing at $55^{\circ} \mathrm{C}$ for $1 \mathrm{~min}$, and elongation at $72{ }^{\circ} \mathrm{C}$ for $2 \mathrm{~min}$, with a final extension for $7 \mathrm{~min}$ at $72{ }^{\circ} \mathrm{C}$. We detected a 1332-base pair (bp) fragment on a $1 \%$ agarose gel after electrophoresis at $100 \mathrm{~V}$ for $60 \mathrm{~min}$. Using $B s t U-I$ as the restriction enzyme, one (1332-bp) and two (291 and 1041-bp) fragments were obtained for $C Y P 2 A 6^{*} 1 \mathrm{~A}$ and $C Y P 2 A 6^{*}$ non$1 \mathrm{~A}$, respectively. Using the restriction enzyme Bsu36-I, three fragments $(104,437$, and 792-bp) were observed for $C Y P 2 A 6^{*} 1 \mathrm{~A}$ or $C Y P 2 A 6^{*} 1 \mathrm{~B}$. Four fragments (64, 104, 437, and 728-bp) were found for CYP2A6*4C. Positive controls were run for each of the genotyping assays. The DNAs of $C Y P 2 A 6^{*} 1 \mathrm{~A} /{ }^{*} 1 \mathrm{~A}, C Y P 2 A 6 * 1 \mathrm{~A} /{ }^{*} 1 \mathrm{~B}$, $C Y P 2 A 6 * 1 \mathrm{~B} / * 1 \mathrm{~B}, C Y P 2 A 6 * 1 \mathrm{~A} / * 4 \mathrm{C}$, and $C Y P 2 A 6 * 1 \mathrm{~B} / * 4 \mathrm{C}$, which have been found in Taiwanese and Chinese populations, were identified by DNA sequencing $[29,30]$. Additional file 1: Table S1 lists the result.

For COMT rs4680, the forward primer 5'-CTGTGGCT ACTCAGCTGTG-3' and reverse primer $5^{\prime}$-CCTT TTTCCAGGTCTGACAA-3' were used to amplify a 169-bp fragment [10]. Using N1a III as the restriction enzyme, three (114, 32, and 23-bp), four (96, 32, 23, and 18-bp), and five $(114,96,32,23$, and 18-bp) fragments were obtained for the G/G, A/A, and G/A genotypes, respectively [10]. For COMT rs165599, the forward primer 5'-CATTCAAAGCTCCCCTTGAC-3' and reverse primer $5^{\prime}$-GGGAGTAGG-GAAGGAGATGC-3' were utilized to amplify a 301-bp fragment [32]. Using Msp $I$ as the restriction enzyme, one (301-bp), two (166 and 135 -bp), and three (301, 166, and 135-bp) fragments were obtained from the $\mathrm{A} / \mathrm{A}, \mathrm{G} / \mathrm{G}$, and $\mathrm{A} / \mathrm{G}$ genotypes, respectively [32].

\section{Determination of urinary nicotine and cotinine}

To evaluate the effects of genetic polymorphisms on the metabolism of nicotine and cotinine, urinary nicotine and cotinine levels of smokers were measured. Gas chromatography-mass spectrometry (GC/MS) was performed as previously described [33], with the following difference: GC-MS analyses were performed on a ThermoElectron DSQII quadrupole mass spectrometer connected directly to a ThermoElectron focus gas chromatograph and an autosampler AS 3000 (Thermo Electron Corporation, Dreieich, Germany). All urine samples were stored at $-20^{\circ} \mathrm{C}$ before analysis. All of the analyses were performed in duplicate and repeated if values differed by $>10 \%$. Tobacco cigarettes currently smoked in Taiwan contain $0.57-0.64 \mathrm{mg}$ of nicotine per cigarette on average [12]. The nicotine and cotinine concentrations in the urine of each subject were divided by the number of daily cigarettes smoked and defined as the adjusted nicotine and adjusted cotinine concentration.

\section{The effects of gene polymorphism interactions on smoking behaviors}

The CYP2A6 genotypes consisted of wild-type ("1A/*1A), high -activity ("1A/*1B and $\left.* 1 \mathrm{~B} /{ }^{*} 1 \mathrm{~B}\right)$, and low-activity $\left(" 1 \mathrm{~A} /{ }^{*} 4 \mathrm{C},{ }^{*} 1 \mathrm{~B} /{ }^{*} 4 \mathrm{C}\right.$, and $\left." 4 \mathrm{C} /{ }^{*} 4 \mathrm{C}\right)$ genotypes. The COMT rs4680 genotypes consisted of wild-type (G/G) and variant (G/A and A/A). The COMT rs165599 genotypes consisted of wild-type (A/A) and variant (A/G and G/G) genotypes. To assess the interaction between the effects of CYP2A6 and COMT gene polymorphisms on smoking behaviors, multiple models were used to analyze the CYP2A6, COMT rs4680, and COMT rs165599 data: (1) 
single gene (model 1: CYP2A6) or single SNP (model 2: COMT rs4680, COMT rs165599, respectively); (2) 2 SNPs (model 3: COMT rs4680 and COMT rs165599); and (3) multiple genes (models 4-7). We evaluated the effect of the interactions between different gene combinations on smoking status (Table 2), smoking intensity (Additional file 2: Table S2), nicotine dependence (FTND), physiological cigarette dependence (PCDS), nicotine toxicity and withdrawal symptoms (CWS-21) (Additional file 3: Table S3), and urine nicotine/cotinine concentration (Table 3) in young men.

\section{Statistical analysis}

To evaluate the effect of the genetic variants on smoking status and smoking intensity, this study assigned an odds ratio (OR) as 1 to subjects carrying the wild-type. The Mantel-Haenszel Chi square test was utilized to calculate the ORs and their 95\% confidence intervals (CIs) (Table 2; Additional file 2: Table S2). To compare the significance of FTND, PCDS, and CWS-21 and to compare the urinary nicotine and cotinine clearance among subjects carrying different CYP2A6 and COMT polymorphisms, Student's $t$ test or analysis of variance (ANOVA), as appropriate, was applied to compare quantitative data. A $P$ value of $<0.05$ was defined as statistically significant for each analysis (Additional file 3: Table S3). When the result of ANOVA was statistically significant, multiple comparisons were followed by application of Scheffés post hoc test. However, if the data in any group did not fit a normal distribution, the Mann-Whitney U test with Bonferroni adjustment was utilized to compare the data between the two groups (Table 3). All data were analyzed using SPSS (version 18.0 software for Windows, SPSS Inc., Chicago, IL).

\section{Results}

We recruited a total of 500 men aged 20-25 years. Analysis of the questionnaires revealed that there were 219 never smokers, 261 current smokers, and 20 ever smokers. Due to the small sample size (moderate power analysis in general, $\alpha=0.05$ and $80 \%$ power requires 200 samples), the 20 ever smokers were excluded from further study. Mean age did not differ between the 261 current smokers and the 219 never smokers $(22.6 \pm 1.69$ vs. $22.4 \pm 1.42, t=1.371, \mathrm{P}=0.176$, data not shown).

The distributions of CYP2A6 and COMT polymorphisms are shown in Table 1 . Using the frequencies of $C Y P 2 A 6 * 1 \mathrm{~A} /{ }^{*} 1 \mathrm{~A}, C Y P 2 A 6^{*} 1 \mathrm{~A} / * 1 \mathrm{~B}$, and $C Y P 2 A 6 * 1 \mathrm{~B} /{ }^{*} 1 \mathrm{~B}$ as examples, the distributions of $C Y P 2 A 6$ genotypes agreed with Hardy-Weinberg equilibrium: $\mathrm{P}=0.713$ and 0.332 for current smokers and never smokers, respectively. The distribution of COMT rs165599 genotypes also agreed with Hardy-Weinberg equilibrium: $\mathrm{P}=0.966$ and 0.668 for current smokers and never smokers, respectively. The distribution of COMT rs4680 genotypes did not agree with Hardy-Weinberg equilibrium: $P=0.003$ and 0.012 for current smokers and never smokers, respectively.

Table 1 Distribution of CYP2A6 and COMT polymorphisms

\begin{tabular}{|c|c|c|c|c|}
\hline Genotypes & $\begin{array}{l}\text { Current smokers } \\
{[n=261(n \%)]}\end{array}$ & $\begin{array}{l}\text { Hardy-Weinberg } \\
\text { equilibrium }\end{array}$ & $\begin{array}{l}\text { Never smokers } \\
{[n=219(n \%)]}\end{array}$ & $\begin{array}{l}\text { Hardy-Weinberg } \\
\text { equilibrium }\end{array}$ \\
\hline CYP2A6 & & $P^{a}=0.713$ & & $P^{a}=0.332$ \\
\hline $1 \mathrm{~A} / 1 \mathrm{~A}$ & $63(24.1)$ & & $46(21.0)$ & \\
\hline $1 \mathrm{~A} / 1 \mathrm{~B}$ & $100(38.3)$ & & $88(40.2)$ & \\
\hline $1 \mathrm{~B} / 1 \mathrm{~B}$ & 44 (16.9) & & $31(14.2)$ & \\
\hline $1 \mathrm{~A} / 4 \mathrm{C}$ & $24(9.2)$ & & $25(11.4)$ & \\
\hline $4 \mathrm{C} / 4 \mathrm{C}$ & $4(1.5)$ & & $3(1.37)$ & \\
\hline $1 \mathrm{~B} / 4 \mathrm{C}$ & $26(10.0)$ & & 26 (11.9) & \\
\hline COMT rs4680 & & $P^{b}=0.003$ & & $\mathrm{P}^{\mathrm{b}}=0.012$ \\
\hline $\mathrm{G} / \mathrm{G}$ & $147(56.3)$ & & $113(51.6)$ & \\
\hline $\mathrm{G} / \mathrm{A}$ & $73(28.0)$ & & $69(31.5)$ & \\
\hline $\mathrm{A} / \mathrm{A}$ & $41(15.7)$ & & $37(16.9)$ & \\
\hline COMTrs165599 & & $P^{c}=0.966$ & & $P^{c}=0.668$ \\
\hline $\mathrm{A} / \mathrm{A}$ & $61(23.4)$ & & 45 (20.6) & \\
\hline$A / G$ & $130(49.8)$ & & $112(51.1)$ & \\
\hline $\mathrm{G} / \mathrm{G}$ & $70(26.8)$ & & $62(28.3)$ & \\
\hline
\end{tabular}

a For CYP2A6 1A/1A, 1A/1B, 1B/1B

b For COMT rs4680

c For COMT rs165599 
Table 2 Odds ratios for the effects of CYP2A6 and COMT polymorphisms on smoking status

\begin{tabular}{|c|c|c|c|c|}
\hline Genotypes interaction & Current smokers $N=261$ & Never smokers $N=219$ & OR $(95 \% \mathrm{Cl})$ & $\mathrm{P}^{\mathrm{a}}$ \\
\hline \multicolumn{5}{|l|}{ Model 1} \\
\hline \multicolumn{5}{|l|}{ CYP2A6 } \\
\hline Wild type & 63 & 46 & 1.0 & \\
\hline High activity & 144 & 119 & $0.88(0.56-1.39)$ & 0.591 \\
\hline Low activity & 54 & 54 & $0.73(0.43-1.25)$ & 0.249 \\
\hline \multicolumn{5}{|l|}{ Model 2} \\
\hline \multicolumn{5}{|l|}{ СОМт } \\
\hline \multicolumn{5}{|l|}{ COMT rs4680 } \\
\hline Wild type & 147 & 113 & 1.0 & \\
\hline Variant & 114 & 106 & $0.83(0.58-1.19)$ & 0.301 \\
\hline \multicolumn{5}{|l|}{ COMT rs165599 } \\
\hline Wild type & 61 & 45 & 1.0 & \\
\hline Variant & 200 & 174 & $0.85(0.55-1.31)$ & 0.458 \\
\hline \multicolumn{5}{|l|}{ Model 3} \\
\hline \multicolumn{5}{|c|}{ COMT rs4680/COMT rs 165599} \\
\hline Wild type/wild type & 27 & 13 & 1.0 & \\
\hline Wild type/variant & 120 & 100 & $0.58(0.28-1.18)$ & 0.128 \\
\hline Variant/wild type & 34 & 32 & $0.51(0.23-1.16)$ & 0.107 \\
\hline Variant/variant & 80 & 74 & $0.52(0.25-1.08)$ & 0.078 \\
\hline \multicolumn{5}{|l|}{ Model 4} \\
\hline \multicolumn{5}{|l|}{ COMT rs4680 wild type } \\
\hline CYP2A6 wild type & 35 & 25 & 1.0 & \\
\hline CYP2A6 high activity & 76 & 65 & $0.84(0.45-1.54)$ & 0.563 \\
\hline CYP2A6 low activity & 36 & 23 & $1.12(0.54-2.33)$ & 0.765 \\
\hline \multicolumn{5}{|l|}{ Model 5} \\
\hline \multicolumn{5}{|l|}{ COMT rs4680 variant } \\
\hline CYP2A6 wild type & 28 & 21 & 1.0 & \\
\hline CYP2A6 high activity & 68 & 54 & $0.94(0.48-1.84)$ & 0.867 \\
\hline CYP2A6 low activity & 18 & 31 & $0.44(0.19-0.98)$ & 0.043 \\
\hline \multicolumn{5}{|l|}{ Model 6} \\
\hline \multicolumn{5}{|l|}{ COMT rs165599 wild type } \\
\hline CYP2A6 wild type & 15 & 8 & 1.0 & \\
\hline CYP2A6 high activity & 33 & 30 & $0.59(0.22-1.58)$ & 0.289 \\
\hline CYP2A6 low activity & 13 & 7 & $0.99(0.28-3.48)$ & 0.988 \\
\hline \multicolumn{5}{|l|}{ Model 7} \\
\hline \multicolumn{5}{|l|}{ COMT rs165599 variant } \\
\hline CYP2A6 wild type & 48 & 38 & 1.0 & \\
\hline CYP2A6 high activity & 111 & 89 & $0.99(0.59-1.64)$ & 0.961 \\
\hline CYP2A6 low activity & 41 & 47 & $0.69(0.38-1.26)$ & 0.224 \\
\hline
\end{tabular}

a Mantel-Haenszel Chi square test

The genotypes of (1) CYP2A6: wild-type $\left({ }^{*} 1 A /{ }^{*} 1 A\right)$, high activity $\left({ }^{*} 1 A /{ }^{*} 1 B\right.$ and $\left.{ }^{*} 1 B /{ }^{*} 1 B\right)$, low activity $\left(* 1 A /{ }^{*} 4 C, * 1 B / * 4 C\right.$, and $\left.* 4 C /{ }^{*} 4 C\right) ;(2)$ COMT rs $4680:$ wild-type $(G / G)$, variant $(G / A$ and $A / A)$; and (3) COMT rs165599: wild-type $(A / A)$, variant $(A / G$ and $G / G)$

As shown in Table 2, after using never smokers as the reference group, the OR was significantly lower in the subjects carrying the genotype of CYP2A6 low activity/ variant $C O M T$ rs4680 than in those possessing the genotype of CYP2A6 wild-type/variant COMT rs4680 (0.44, 95\% CI 0.19-0.98, $\mathrm{P}=0.043)$. The other 14 ORs were not statistically significant $(\mathrm{P}=0.078-0.988)$.
The average number of cigarettes per day among the 261 current smokers was 10 . There were 127 heavy smokers and 131 light smokers (data for three smokers were missing). With light smokers as the reference group, 15 ORs for heavy smoking were not statistically significant $(\mathrm{P}=0.061-0.112$, data in Additional file 2: Table S2). 
Table 3 Comparisons of adjusted urinary nicotine concentration and adjusted urinary cotinine concentration among subjects $(N=122)$ carrying different CYP2A6 and COMT polymorphisms

\begin{tabular}{|c|c|c|c|}
\hline & $\mathrm{N}$ & $\begin{array}{l}\text { Adjusted urinary nicotine, } \\
\mathrm{ng} / \mu \mathrm{L} \text { median (min-max) }\end{array}$ & $\begin{array}{l}\text { Adjusted urinary cotinine, } \\
\mathrm{ng} / \mu \mathrm{L} \text { median (min-max) }\end{array}$ \\
\hline \multicolumn{4}{|l|}{ Model 1} \\
\hline \multicolumn{4}{|l|}{ CYP2A6 } \\
\hline Wild type & 17 & $86.23(6.14-296.36)$ & $120.90(20.39-485.32)$ \\
\hline High activity & 76 & 70.45 (6.28-1117.87) & $111.08(8.34-822.11)$ \\
\hline Low activity & 29 & $61.59(15.28-456.87)$ & 75.87 (10.87-266.44) \\
\hline$p^{a}$ & & NS & NS \\
\hline \multicolumn{4}{|l|}{ Model 2} \\
\hline \multicolumn{4}{|l|}{ COMT } \\
\hline \multicolumn{4}{|l|}{ COMT rs4680 } \\
\hline Wild type & 66 & $63.86(6.28-646.38)$ & $92.46(8.34-506.97)$ \\
\hline Variant & 56 & $67.87(6.14-1117.87)$ & $118.24(13.59-822.11)$ \\
\hline $\mathrm{p}^{\mathrm{a}}$ & & NS & 0.041 \\
\hline \multicolumn{4}{|l|}{ COMT rs165599 } \\
\hline Wild type & 27 & $68.10(12.42-212.74)$ & 89.42 (23.06-218.62) \\
\hline Variant & 95 & $64.11(6.14-1117.87)$ & $107.24(8.34-822.11)$ \\
\hline$p^{a}$ & & NS & NS \\
\hline \multicolumn{4}{|l|}{ Model 3} \\
\hline \multicolumn{4}{|c|}{ COMT rs4680/COMT rs 165599} \\
\hline Wild type/wild type & 13 & $89.29(12.42-212.74)$ & 79.37 (23.06-218.62) \\
\hline Wild type/variant & 53 & $63.61(6.28-646.38)$ & $97.10(8.34-506.97)^{*}$ \\
\hline Variant/wild type & 14 & $67.87(15.28-177.61)$ & $95.86(32.18-202.0)$ \\
\hline Variant/variant & 42 & $69.46(6.14-1117.87)$ & $122.18(13.59-822.11)^{*}$ \\
\hline $\mathrm{P}^{\mathrm{a}}$ & & NS & \\
\hline \multicolumn{4}{|l|}{ Model 4} \\
\hline \multicolumn{4}{|l|}{ COMT rs4680 wild type } \\
\hline CYP2A6 wild type & 9 & 95.04 (25.04-296.36) & $105.70(53.48-485.32)$ \\
\hline CYP2A6 high activity & 39 & 72.99 (6.28-646.38) & $97.45(8.34-506.97)$ \\
\hline CYP2A6 low activity & 18 & 42.54 (19.38-371.29) & $60.20(10.87-266.44)$ \\
\hline$P^{a}$ & & NS & NS \\
\hline \multicolumn{4}{|l|}{ Model 5} \\
\hline \multicolumn{4}{|l|}{ COMT rs4680 variant } \\
\hline CYP2A6 wild type & 8 & $74.91(6.14-217.41)$ & 141.53 (20.39-228.68) \\
\hline CYP2A6 high activity & 37 & $68.10(17.68-1117.87)$ & $115.78(13.59-822.11)$ \\
\hline CYP2A6 low activity & 11 & $66.13(15.28-456.87)$ & 161.65 (39.19-224.53) \\
\hline$p^{a}$ & & NS & NS \\
\hline \multicolumn{4}{|l|}{ Model 6} \\
\hline \multicolumn{4}{|l|}{ COMT rs 165599 wild type } \\
\hline CYP2A6 wild type & 3 & 95.04 (62.36-188.57) & $102.30(79.37-120.90)$ \\
\hline CYP2A6 high activity & 17 & 67.64 (12.42-212.74) & 89.42 (32.18-218.62) \\
\hline CYP2A6 low activity & 7 & 78.05 (15.28-177.61) & 63.55 (23.06-202.00) \\
\hline $\mathrm{p}^{\mathrm{a}}$ & & NS & NS \\
\hline
\end{tabular}

For the 261 current smokers, FTND, PCDS, and CWS-21 were analyzed for 181,227 , and 210 subjects, respectively, because of missing data. Each of the eight comparisons for FTND, PCDS, and CWS-21 among the groups with different CYP2A6/COMT polymorphisms was not significantly different $(\mathrm{P}=0.224-0.911,0.054-$ 0.700 , and $0.075-0.836$, respectively) (data in Additional file 3: Table S3).

Of the 261 current smokers, 122 subjects provided urine samples for the determination of nicotine and 
Table 3 continued

\begin{tabular}{llll}
\hline & $\mathbf{N}$ & $\begin{array}{l}\text { Adjusted urinary nicotine, } \\
\mathbf{n g} / \boldsymbol{\mu L} \text { median (min-max) }\end{array}$ & $\begin{array}{l}\text { Adjusted urinary cotinine, } \\
\mathbf{n g} / \boldsymbol{\mu L} \text { median (min-max) }\end{array}$ \\
\hline $\begin{array}{l}\text { Model 7 } \\
\text { COMT rs165599 variant }\end{array}$ & & & $141.53(20.39-485.32)$ \\
CYP2A6 wild type & 14 & $74.92(6.14-296.36)$ & $111.09(8.34-822.11)$ \\
CYP2A6 high activity & 59 & $72.99(6.28-1117.87)$ & $81.66(10.87-266.44)$ \\
CYP2A6 low activity & 22 & $59.62(19.38-456.87)$ & NS \\
Pa & & NS & \\
\hline
\end{tabular}

NS not statistically significant

a Mann-Whitney U test or Kruskal-Wallis test with Bonferroni adjustment

* Significantly different from the (COMT rs4680 wild-type/COMT rs165599 variant) group versus the (COMT rs4680 variant/COMT rs165599 variant) group by Scheffe's Post hoc test, $P$ value $=0.022$

cotinine levels by GC/MS. The values for adjusted nicotine concentration and adjusted cotinine concentration were not normally distributed in either genotype group. The SD was too high: near the mean value or even greater than the mean value. Therefore, the Mann-Whitney U test or Kruskal-Wallis test with Bonferroni adjustment was used for comparison of the values of adjusted nicotine concentration and adjusted cotinine concentration between groups carrying different genotypes. As shown in Table 3, the adjusted urinary nicotine concentration did not differ significantly in any of the comparisons. The median adjusted urinary cotinine concentration differed between the COMT rs4680 wild-type group and the COMT rs4680 variant group (92.46 ng/ $\mu \mathrm{L}$ vs. $118.24 \mathrm{ng} /$ $\mu \mathrm{L}, \mathrm{P}=0.041$ ) and between the COMT rs4680 wildtype/COMT rs165599 variant group and the COMT rs4680 variant/COMT rs165599 variant group $(97.10 \mathrm{ng} /$ $\mu \mathrm{L}$ vs. $122.18 \mathrm{ng} / \mu \mathrm{L}, \mathrm{P}=0.022)$. The other comparisons were not statistically significant.

\section{Discussion}

All subjects in this study were young adult university students. Alcohol and drug abusers were excluded. Therefore, the effects of age, education status and alcohol and drug interactions on smoking were absent.

Our results show that the distribution of COMT rs4680 does not agree with Hardy-Weinberg equilibrium, consistent with reports that Asiatic individuals have Hardy-Weinberg disequilibrium of the COMT rs4680 polymorphism [8]. The main finding of this study is that among adult males with variant COMT rs4680, the subjects carrying the low-activity genotype of $C Y P 2 A 6$ have a 0.44-fold lower risk of starting smoking than those possessing the wild-type genotype of CYP2A6. In other words, the OR is 2.27 -fold higher in subjects carrying the CYP2A6 wild-type/variant COMT rs4680 genotype than in those possessing the $C Y P 2 A 6$ low activity/variant
COMT rs4680 genotype. The CYP2A6 and COMT genes were reported to be associated with smoking status. $C Y P 2 A 6^{*} 4 \mathrm{C}$ is a whole-deletion type, decreased nicotine metabolism polymorphism [34]. In Japanese adults and young Japanese students, the frequency of the $C Y P 2 A 6 * 4 C$ gene was significantly higher among nonsmokers than smokers [34, 35]. Among Chinese males, participants with the CYP2A6*4C genotype had a lower risk of smoking initiation and smoking persistence than those with the $C Y P 2 A 6^{*} 1 / C Y P 2 A 6^{*} 1$ genotype [17]. For people living in southern China, reduced metabolic function of CYP2A6 in smokers appears to be associated with fewer cigarettes smoked, later initiation of smoking regularly, shorter smoking duration, and lower likelihood of smoking cessation [36]. For Caucasian individuals, the CYP2A6 slow inactivator genotype increased the risk of nicotine dependence when smoking was initiated during adolescence. However, it reduced the risk of smoking initiation, lowered cigarette consumption, and decreased the duration of smoking among adult dependent smokers [37]. The continued effect of slow metabolism on reducing cigarette consumption, throughout the smoking history of people with $C Y P 2 A 6$ slow inactivators, may affect tolerance and withdrawal mechanisms among these individuals [37]. Smokers with $C Y P 2 A 6$ slow inactivators smoke fewer cigarettes and tend to be less dependent on nicotine than smokers with normal activity alleles [38]. With respect to smoking initiation, adolescents with slower activity alleles may progress to nicotine dependence more slowly than normal metabolizers [38]. Very recently, researchers reported that CYP2A6 slow metabolism was associated with increased adolescent smoking cessation in Caucasian individuals [39]. The ORs for current smoking are reportedly higher in COMT rs4680 G/G (the high activity allele) carriers than in those possessing the COMT rs4680 variant among healthy Caucasian men of Croatian origin [40], Americans of European 
ancestry [41], and Japanese men [15]. On the other hand, the COMT rs4680 variation (G/A or A/A, the low-activity alleles) was associated with nicotine dependence in men and women of African-American and EuropeanAmerican descent [9], smoking severity among Chinese male smokers [42], heaviness of smoking in Caucasian pregnant women [43], and susceptibility to cigarette smoking among Thai males [11]. Our results demonstrate for the first time that the combination of the low-activity CYP2A6 genotype and low-activity COMT genotype is associated with the risk of starting smoking.

We also found that the adjusted urinary cotinine concentration was higher in subjects with low-activity COMT genes than in those with high-activity COMT genes. Additionally, it was higher in subjects with the COMT rs4680 variant/COMT rs165599 variant than in those with the COMT rs4680 wild-type/COMT rs165599 variant. The urinary cotinine concentration is a reliable easy-to-use marker for plasma levels of cotinine and the sum of nicotine metabolites in smokers [44]. Therefore, our findings indicate that cotinine and the sum of nicotine metabolites are metabolized more slowly in subjects carrying the low-activity genotype than in those possessing the high-activity genotype. However, such a difference did not affect FTND, PCDS, or CWS-21 scores, and it was not related to the risk of heavier smoking. The smoking intensity of the university students was lower (average cigarettes/day $=10$ and average FTND score $=3.7$ ) than that of Taiwanese adult smokers, e.g., average cigarettes/day $=24$ and average FTND score $=7.1$ for Chinese adults [42]. This finding may be the reason, at least in part, that the low activity genotypes of CYP2A6 and COMT were associated with high nicotine dependence scores and heavier smoking, as we reported in this study. For Taiwanese university students, the primary reason for the first contact with smoking was curiosity. Anxiety, avoiding stress, and the difficulties of smoking cessation explained continuing smoking behavior among university students [45]. The environmental factors may be more predominant than certain genetic factors (e.g., polymorphisms of CYP2A6 and COMT genes) among Taiwanese smokers in the university setting.

There are several limitations to our study. The percentage of female smokers in the Taiwanese population is low, only $4.4 \%$, and they are difficult to recruit as participants. In our report, study participation was restricted to young male Taiwanese smokers. Although the total number of study subjects was relatively large, the numbers of individuals with some of the genotypes were too small to reach statistically significant power. Therefore, further studies with a larger sample size and that include female smokers are needed.

\section{Conclusions}

A single nucleotide polymorphism (rs4680) in the COMT gene and the interaction between the CYP2A6 and $C O M T$ genes affect smoking status in young Taiwanese men. Effective smoking prevention and cessation intervention programs are required to reduce smoking among university students [46]. We found that the interaction of the low-activity CYP2A6 genotype and low-activity COMT genotype is associated with the risk of starting smoking. In addition, interaction of the DRD2 TaqIB and $M A O A$ genes also affects smoking intensity in Taiwanese young men [14]. This knowledge is useful for developing an approach to reducing smoking among Taiwanese university students. A clearer understanding of the relative roles of genetic and non-genetic factors in the initiation of smoking could have implications for the design of smoking prevention programs [47].

\section{Additional files}

Additional file 1: Table S1. Results of PCR-RFLP fragments for CYP2A6.

Additional file 2: Table S2. Odds ratios for the effect of CYP2A6 and COMT.

Additional file 3: Table S3. Comparisons of FTND, PCDS and CWS-21 among subjects carrying different CYP2A6 and COMT polymorphisms.

\section{Abbreviations}

CYP2A6: cytochrome P450 2A6; COMT: catechol-O-methyltransferase; FTND: Fagerstrom Test for Nicotine Dependence; PCDS: Physiological Cigarette Dependence Scale; CWS: Cigarette Withdrawal Symptoms Scale.

\section{Authors' contributions}

Conceived and designed the experiments: WCO, PLC, CSH. Performed the experiments: WCO, PLC, MHL, YJC, CNL, and MCC. Analyzed the data: CLH, YCC,YCH. Wrote the paper: $\mathrm{CSH}, \mathrm{PLC}, \mathrm{YCH}$. All authors read and approved the final manuscript.

\section{Author details}

1 Department of Medical Laboratory Science and Biotechnology, Central Taiwan University of Science and Technology, No. 666 Buzih Road, Beitun District, Taichung City 40601, Taiwan. ${ }^{2}$ Department of Nursing, Chang Jung Christian University, Tainan, Taiwan. ${ }^{3}$ Administration Center for Research and Education, Changhua Christian Hospital, Changhua, Taiwan. ${ }^{4}$ Company Limited of Ditech Enterprise, Taipei, Taiwan. ${ }^{5}$ Division of Infectious Diseases, Jen-Ai Hospital, Taichung, Taiwan.

\section{Acknowledgements}

We express our deep appreciation to the National Science Council of Taiwan (Grant NSC-100-2320-B-371-001), Changhua Christian Hospital, Taiwan (Grant CCH-ICO10008).

\section{Competing interests}

The authors declared that they have no competing interests.

\section{Availability of data and materials}

The authors confirm that all data and materials underlying the findings are fully available without restriction. All relevant data are within the paper.

Consent for publication

Informed consent to publish was obtained from the patients in this research. 


\section{Ethics approval and consent to participate}

This study was approved by the review board of Chang Jung Christian University (CJCU-99004) and the ethics board of the Central Taiwan University of Science and Technology (CTUST-99016). It was conducted in accordance with Good Clinical Practice procedures and the Declaration of Helsinki.

\section{Funding}

This study was financially supported by Central Taiwan University of Science and Technology (Grant CTU103-P-20, CTU103-P-21).

\section{Publisher's Note}

Springer Nature remains neutral with regard to jurisdictional claims in published maps and institutional affiliations.

Received: 30 September 2016 Accepted: 26 April 2017

Published online: 04 May 2017

\section{References}

1. Quaak M, van Schayck CP, Knaapen AM, van Schooten FJ. Genetic variation as a predictor of smoking cessation success. A promising preventive and intervention tool for chronic respiratory diseases? Eur Respir J. 2009:33:468-80

2. Kim YS, Ko H, Yoon C, Lee DH, Sung J. Social determinants of smoking behavior: the healthy twin study, Korea. J Prev Med Public Health. 2012:45:29-36.

3. Wright AJ, French DP, Weinman J, Marteau TM. Can genetic risk information enhance motivation for smoking cessation? An analogue study. Health Psychol. 2006;25:740-52.

4. Tsuang MT, Francis T, Minor K, Thomas A, Stone WS. Genetics of smoking and depression. Hum Genet. 2012;131:905-15.

5. Di YM, Chow VD, Yang LP, Zhou SF. Structure, function, regulation and polymorphism of human cytochrome P450 2A6. Curr Drug Metab. 2009:10:754-80

6. Benowitz NL, Hukkanen J, Jacob P. 3rd. Nicotine chemistry, metabolism, kinetics and biomarkers. Handb Exp Pharmacol. 2009;192:29-60.

7. Mwenifumbo JC, Myers MG, Wall TL, Lin SK, Sellers EM, Tyndale RF. Ethnic variation in CYP2A6*7, CYP2A6*8 and CYP2A6*10 as assessed with a novel haplotyping method. Pharmacogenetics Genom. 2005;15:189-92.

8. Jimenez-Jimenez FJ, Alonso-Navarro H, Garcia-Martin E, Agundez JA. COMT gene and risk for Parkinson's disease: a systematic review and meta-analysis. Pharmacogenetics Genom. 2014;24:331-9.

9. Beuten J, Payne TJ, Ma JZ, Li MD. Significant association of catecholO-methyltransferase (COMT) haplotypes with nicotine dependence in male and female smokers of two ethnic populations. Neuropsychopharmacology. 2006;31:675-84.

10. Berrettini WH, Wileyto EP, Epstein L, Restine S, Hawk L, Shields P, Niaura R, Lerman C. Catechol-O-methyltransferase (COMT) gene variants predict response to bupropion therapy for tobacco dependence. Biol Psychiatry. 2007:61:111-8.

11. Suriyaprom $K$, Tungtrongchitr $R$, Harnroongroj T. Impact of COMT Val 108/158 Met and DRD2 Taq1B gene polymorphisms on vulnerability to cigarette smoking of Thai males. J Mol Neurosci. 2013;49:544-9.

12. Health Promotion Administration. Taiwan tobacco control: annual report 2012. 2013. http://health99.hpa.gov.tw/media/public/zip/21747.zip. Accessed 24 Apr 2016

13. Chen YT, Tsou HH, Kuo HW, Fang CP, Wang SC, Ho IK, Chang YS, Chen $\mathrm{CH}, \mathrm{Hsiao} \mathrm{CF}$, Wu HY, et al. OPRM1 genetic polymorphisms are associated with the plasma nicotine metabolite cotinine concentration in methadone maintenance patients: a cross sectional study. J Hum Genet. 2013;58:84-90.

14. Huang $\mathrm{CL}$, Ou WC, Chen PL, Liu CN, Chen MC, Lu CC, Chen YC, Lin MH, Huang CS. Effects of interaction between dopamine D2 receptor and monoamine oxidase a genes on smoking status in young men. Biol Res Nurs. 2015;17:422-8.

15. Tochigi M, Suzuki K, Kato C, Otowa T, Hibino H, Umekage T, Kato N, Sasaki T. Association study of monoamine oxidase and catechol-O-methyltransferase genes with smoking behavior. Pharmacogenetics Genom. 2007:17:867-72
16. Shiels MS, Huang HY, Hoffman SC, Shugart YY, Bolton JH, Platz EA, Helzlsouer KJ, Alberg AJ. A community-based study of cigarette smoking behavior in relation to variation in three genes involved in dopamine metabolism: Catechol-O-methyltransferase (COMT), dopamine betahydroxylase (DBH) and monoamine oxidase-A (MAO-A). Prev Med. 2008:47:116-22.

17. Tang X, Guo S, Sun H, Song X, Jiang Z, Sheng L, Zhou D, Hu Y, Chen D. Gene-gene interactions of CYP2A6 and MAOA polymorphisms on smoking behavior in Chinese male population. Pharmacogenetics Genom. 2009;19:345-52.

18. Rodriguez S, Cook DG, Gaunt TR, Nightingale CM, Whincup PH, Day IN. Combined analysis of CHRNA5, CHRNA3 and CYP2A6 in relation to adolescent smoking behaviour. J Psychopharmacol. 2011;25:915-23.

19. Wassenaar CA, Dong Q, Wei Q, Amos Cl, Spitz MR, Tyndale RF. Relationship between CYP2A6 and CHRNA5-CHRNA3-CHRNB4 variation and smoking behaviors and lung cancer risk. J Natl Cancer Inst. 2011;103:1342-6.

20. Ohmoto M, Takahashi T, Kubota Y, Kobayashi S, Mitsumoto Y. Genetic influence of dopamine receptor, dopamine transporter, and nicotine metabolism on smoking cessation and nicotine dependence in a Japanese population. BMC Genet. 2014;15:151.

21. Doran N. Sex differences in smoking cue reactivity: craving, negative affect, and preference for immediate smoking. Am J Addict. 2014:23:211-7.

22. Huang $\mathrm{CL}$, Cheng $\mathrm{CP}$, Huang HW. The development of a Chineselanguage instrument to measure social smoking motives among male Taiwanese smokers. J Transcult Nurs. 2013;24:371-7.

23. Mwenifumbo JC, Lessov-Schlaggar CN, Zhou Q, Krasnow RE, Swan GE, Benowitz NL, Tyndale RF. Identification of novel CYP2A6*1B variants: the CYP2A6*1B allele is associated with faster in vivo nicotine metabolism. Clin Pharmacol Ther. 2008;83:115-21.

24. Schoedel KA, Hoffmann EB, Rao Y, Sellers EM, Tyndale RF. Ethnic variation in CYP2A6 and association of genetically slow nicotine metabolism and smoking in adult Caucasians. Pharmacogenetics. 2004;14:615-26.

25. Huang $\mathrm{CL}$, Lin $\mathrm{HH}$, Wang HH. The psychometric properties of the Chinese version of the fagerstrom test for nicotine dependence. Addict Behav. 2006:31:2324-7.

26. Lu CC, Lin HH, Chen CJ, Huang CL. Psychometric testing of the Chinese version of the dimensions of Tobacco Dependence Scale. J Clin Nurs. 2009;18:2470-7.

27. Huang $\mathrm{CL}$, Lin $\mathrm{HH}$, Wang HH. Cigarette dependence questionnaire: development and psychometric testing with male smokers. J Adv Nurs. 2010;66:2341-9.

28. Raunio H, Rahnasto-Rilla M. CYP2A6: genetics, structure, regulation, and function. Drug Metabol Drug Interact. 2012;27:73-88.

29. Nurfadhlina M, Foong K, Teh LK, Tan SC, Mohd Zaki S, Ismail R. CYP2A6 polymorphisms in Malays, Chinese and Indians. Xenobiotica. 2006;36:684-92.

30. Oscarson M, McLellan RA, Gullsten H, Yue QY, Lang MA, Bernal ML, Sinues B, Hirvonen A, Raunio H, Pelkonen O, Ingelman-Sundberg M. Characterisation and PCR-based detection of a CYP2A6 gene deletion found at a high frequency in a Chinese population. FEBS Lett. 1999;448:105-10.

31. Chiang CT. The polymorphisms of CYP2A6 among Taiwanese lung cancer patients. Master's thesis. Chunghua University (Tainan, Taiwan). 2006. http://handle.ncl.edu.tw/11296/ndltd/29131916603407156420. Accessed 24 Apr 2016.

32. Chan RC, Chen RY, Chen EY, Hui TC, Cheung EF, Cheung HK, Sham P, Li T, Collier D. The differential clinical and neurocognitive profiles of COMT SNP rs165599 genotypes in schizophrenia. J Int Neuropsychol Soc. 2005;11:202-4

33. Dempsey D, Tutka P, Jacob P 3rd, Allen F, Schoedel K, Tyndale RF, Benowitz NL. Nicotine metabolite ratio as an index of cytochrome P450 2A6 metabolic activity. Clin Pharmacol Ther. 2004;76:64-72.

34. Iwahashi K, Waga C, Takimoto T. Whole deletion of CYP2A6 gene (CYP2A6AST;4C) and smoking behavior. Neuropsychobiology. 2004;49:101-4

35. Waga C, Iwahashi K. CYP2A6 gene polymorphism and personality traits for NEO-FFI on the smoking behavior of youths. Drug Chem Toxicol. 2007:30:343-9.

36. Liu T, David SP, Tyndale RF, Wang H, Zhou Q, Ding P, He YH, Yu XQ, Chen W, Crump C, et al. Associations of CYP2A6 genotype with smoking behaviors in southern China. Addiction. 2011;106:985-94. 
37. O'Loughlin J, Paradis G, Kim W, DiFranza J, Meshefedjian G, McMillanDavey E, Wong S, Hanley J, Tyndale RF. Genetically decreased CYP2A6 and the risk of tobacco dependence: a prospective study of novice smokers. Tob Control. 2004;13:422-8.

38. Gold AB, Lerman C. Pharmacogenetics of smoking cessation: role of nicotine target and metabolism genes. Hum genet. 2012;131(6):857-76.

39. Chenoweth MJ, O'Loughlin J, Sylvestre MP, Tyndale RF. CYP2A6 slow nicotine metabolism is associated with increased quitting by adolescent smokers. Pharmacogenetics Genom. 2013;23:232-5.

40. Nedic G, Nikolac M, Borovecki F, Hajnsek S, Muck-Seler D, Pivac N. Association study of a functional catechol-O-methyltransferase polymorphism and smoking in healthy Caucasian subjects. Neurosci Lett. 2010;473:216-9.

41. Redden DT, Shields PG, Epstein L, Wileyto EP, Zakharkin SO, Allison DB, Lerman C. Catechol-O-methyl-transferase functional polymorphism and nicotine dependence: an evaluation of non replicated results. Cancer Epidemiol Biomark Prev. 2005;14:1384-9.

42. Guo S, da Chen F, Zhou DF, Sun HQ, Wu GY, Haile CN, Kosten TA, Kosten TR, Zhang XY. Association of functional catechol O-methyl transferase (COMT) Val108Met polymorphism with smoking severity and age of smoking initiation in Chinese male smokers. Psychopharmacology. 2007;190:449-56.
43. Munafo MR, Freathy RM, Ring SM, St Pourcain B, Smith GD. Association of COMT Val(108/158)Met genotype and cigarette smoking in pregnant women. Nicotine Tob Res. 2011;13:55-63.

44. Nagano T, Shimizu M, Kiyotani K, Kamataki T, Takano R, Murayama N, Shono F, Yamazaki H. Biomonitoring of urinary cotinine concentrations associated with plasma levels of nicotine metabolites after daily cigarette smoking in a male Japanese population. Int J Environ Res Public Health. 2010;7:2953-64.

45. Wang KY, Yang CC, Chu NF, Wu DM. Predictors of cigarette smoking behavior among military university students in Taiwan. J Nurs Res. 2009:17:161-9.

46. Eticha T, Kidane F. The prevalence of and factors associated with current smoking among College of Health Sciences students, Mekelle University in northern Ethiopia. PLoS ONE. 2014;9:e111033.

47. Wilkinson AV, Swartz MD, Yu X, Spitz MR, Shete S. Cigarette experimentation and the population attributable fraction for associated genetic and non-genetic risk factors. PLoS ONE. 2013;8:e53868.

\section{Submit your next manuscript to BioMed Central and we will help you at every step:}

- We accept pre-submission inquiries

- Our selector tool helps you to find the most relevant journal

- We provide round the clock customer support

- Convenient online submission

- Thorough peer review

- Inclusion in PubMed and all major indexing services

- Maximum visibility for your research

Submit your manuscript at www.biomedcentral.com/submit 